CLINICAL RESEARCH ARTICLE

\title{
Glucocorticoids, sodium transport mediators, and respiratory distress syndrome in preterm infants
}

Liina Süvari $^{1,2}$, Otto M. Helve ${ }^{1}$, M. Anneli Kari ${ }^{1}$, L. Ursula Turpeinen ${ }^{3}$, P. Anniina Palojärvi ${ }^{1}$, Markus J. Leskinen ${ }^{1}$, Sture Andersson ${ }^{1}$ and A. Cecilia Janér ${ }^{1}$

BACKGROUND: Antenatal glucocorticoids (GCs) reduce respiratory distress syndrome (RDS) in preterm infants and are associated with reduced lung liquid content. Our aim was to assess whether airway gene expression of mediators of pulmonary epithelial sodium and liquid absorption, and further, respiratory morbidity, associate with cord blood GC concentrations.

METHODS: The study included 64 infants delivered $<32$ weeks gestation. Cortisol and betamethasone in umbilical cord blood were quantified with liquid chromatography-tandem mass spectrometry. The total GC concentration was calculated. Gene expression of the epithelial sodium channel (ENaC), Na,K-ATPase, and serum- and GC-inducible kinase 1 at $<2 \mathrm{~h}$ and at 1 day postnatally in nasal epithelial cell samples was quantified with reverse transcription-polymerase chain reaction. The mean oxygen supplementation during the first $72 \mathrm{~h}$ was calculated.

RESULTS: Concentrations of cord blood betamethasone and total GC were significantly lower in infants with RDS and correlated with mean oxygen supplementation. Expression of $\mathrm{aENaC}$ and $\mathrm{a} 1-$ and $\beta 1 \mathrm{Na}, \mathrm{K}-\mathrm{ATPase}$ at $<2 \mathrm{~h}$ correlated with betamethasone and total GC concentrations. Expression of Na,K-ATPase was lower in infants with RDS.

CONCLUSION: Enhancement of lung liquid absorption via increased expression of sodium transporters may contribute to the beneficial pulmonary effects of antenatal GCs.

Pediatric Research (2021) 89:1253-1260; https://doi.org/10.1038/s41390-020-1061-9

\section{IMPACT:}

- RDS is related to lower umbilical cord blood GC concentrations and lower airway expression of sodium transporters.

- In addition to the timing of antenatal GC treatment, resulting concentrations may be of importance in preventing RDS.

- Induction of sodium transport may be a factor contributing to the pulmonary response to antenatal GCs.

\section{INTRODUCTION}

Respiratory distress syndrome (RDS) remains an important cause of morbidity affecting nearly $80 \%$ of very low birthweight infants (www.vtoxford.org). Before 35 weeks of gestation, maternally administered antenatal glucocorticoids (GCs) reduce RDS in infants by approximately one-third and moderate or severe RDS by $41 \%$, with induction of surfactant synthesis being an important mediating mechanism. ${ }^{1}$ Therefore, antenatal GCs are recommended when delivery before 34 weeks gestation is anticipated within 1 week. ${ }^{2,3}$ The optimal interval between treatment and delivery is considered to be 1-7 days after the first dose. ${ }^{2,3}$ If the infant remains undelivered $>7-14$ days after the initial treatment course, repeated dosing reduces the need for respiratory support. ${ }^{2,4}$ Importantly, antenatal GCs reduce the risk of perinatal and neonatal death, and also, for example, intraventricular hemorrhage and necrotizing enterocolitis. ${ }^{1}$ However, potential complications exist particularly with repeated dosing, since it results in decreased fetal growth. ${ }^{4}$ Further, data on adverse long-term effects are limited. ${ }^{2}$
Excess lung liquid is associated with respiratory distress and, in addition to surfactant deficiency, is a feature of RDS in preterm infants. ${ }^{5,6}$ Antenatal GCs reduce lung liquid content during the immediate postnatal period ${ }^{7}$ and improve lung function in animal models as well as in human preterm infants. ${ }^{8,9}$ GCs induce airway and lung epithelial sodium transporters creating osmotic pressure gradients that promote lung liquid clearance. ${ }^{10}$ During postnatal pulmonary adaptation, the first breaths result in a substantial part of aeration of the lungs, and thus clearance of lung liquid. ${ }^{11,12}$ However, the epithelial sodium channel $(\mathrm{ENaC})$ reduces re-entry of liquid into the airways during expiration ${ }^{11}$ and, according to animal models, is critical for neonatal lung liquid clearance. ${ }^{13,14}$ Indeed, in preterm infants developing RDS both maximal and ENaCmediated sodium transport over the nasal epithelium is decreased. ${ }^{15}$ The absorption of sodium through apical sodium channels is paralleled by extrusion by basolateral $\mathrm{Na}, \mathrm{K}$-ATPase. ${ }^{16}$ In adult human lung, nearly half of basal alveolar liquid clearance has been attributed to Na,K-ATPase. ${ }^{17}$ Perinatally, lung liquid absorption can be augmented by the serum- and

\footnotetext{
${ }^{1}$ Children's Hospital, Pediatric Research Center, Helsinki University and Helsinki University Hospital, Helsinki, Finland; ${ }^{2}$ West Tallinn Central Hospital, Tallinn, Estonia and ${ }^{3}$ HUSLAB, Helsinki University Hospital, Helsinki, Finland

Correspondence: A Cecilia Janér (cecilia.janer@helsinki.fi)
}

Received: 4 March 2020 Revised: 9 June 2020 Accepted: 22 June 2020

Published online: 14 July 2020 
Table 1. Clinical characteristics of the study population.

\begin{tabular}{|c|c|c|c|c|}
\hline & All infants $(n=64)$ & $\operatorname{RDS}(n=28)$ & No $\operatorname{RDS}(n=36)$ & $P$ value (RDS vs. no RDS) \\
\hline Birthweight $(g)$, mean (SD) & $1194(339)$ & $1105(301)$ & $1264(354)$ & 0.06 \\
\hline 1-min Apgar score, median (range) & $6(1-9)$ & $6(2-9)$ & $6(1-9)$ & 0.82 \\
\hline Cesarean delivery, $n$ (\%) & $45(70 \%)$ & $25(89 \%)$ & $20(56 \%)$ & 0.005 \\
\hline Male gender, $n(\%)$ & $33(52 \%)$ & $14(50 \%)$ & $19(53 \%)$ & 0.83 \\
\hline PPROM, $n(\%)$ & $11(17 \%)$ & $3(11 \%)$ & $14(39 \%)$ & 0.02 \\
\hline Confirmed chorioamnionitis, $n^{\mathrm{a}}(\%)$ & $14(22 \%)$ & $3(11 \%)$ & $11(31 \%)$ & 0.03 \\
\hline Maternal pre-eclampsia or hypertension, $n$ (\%) & $22(34 \%)$ & $13(46 \%)$ & $9(25 \%)$ & 0.07 \\
\hline $\mathrm{SGA}, n(\%)$ & $13(20 \%)$ & $6(21 \%)$ & $7(19 \%)$ & 0.85 \\
\hline Doses of surfactant $0-72 \mathrm{~h}: 0 / 1 / 2$ or more, $n$ & $22 / 24 / 18$ & $4 / 8 / 16$ & $18 / 16 / 2$ & $<0.001$ \\
\hline
\end{tabular}

PPROM preterm premature rupture of membranes, RDS respiratory distress syndrome, SGA small for gestational age.

aExcluding 12 infants with clinician suspicion of chorioamnionitis without confirmation by amniotic fluid or placental histopathological examination.

GC-inducible kinase 1 (SGK1) via induction of transepithelial sodium transport. ${ }^{10}$

Our aims were, in preterm infants born $<32$ weeks of gestation, first, to measure the concentrations of GCs in umbilical cord blood achieved by antenatal GC treatment. Second, we assessed the association of indicators of respiratory morbidity, that is, RDS and oxygen requirement, with GC concentrations. Finally, we hypothesized that the gene expression of the mediators of sodium transport in the airway epithelium associates with cord blood GC concentrations and with respiratory morbidity.

\section{METHODS}

Study design and subjects

The prospective cross-sectional cohort study was conducted at the tertiary obstetric unit of the Women's Hospital and the neonatal intensive care unit of the Children's Hospital, Helsinki University Hospital, June 2007 to November 2008 and October 2011 to June 2013. The study periods were determined by recruitment of the patients in conjunction with two other studies. The study was approved by the local hospital ethics committee. We recruited pregnant mothers with threatened preterm delivery before 32 weeks gestational age (GA) receiving antenatal GCs to include their infants in the study. We received the parents' written, informed consent for 64 infants, including 12 A-twins, of whom 24 were born in 2007/2008 and 40 from 2011 to 2013. The causes of prematurity included preterm premature rupture of membranes (PPROM) and chorioamnionitis, pre-eclampsia and/or fetal growth restriction and fetal distress, and preterm labor of unknown etiology.

The standard course of antenatal GC treatment consisted of two intramuscular doses of $12 \mathrm{mg}$ betamethasone (BM) acetate and phosphate (Celeston ${ }^{\circledR}$ Chronodose, Schering-Plough/Merck \& Co., Inc., Whitehouse Station, NJ) with a 24-h interval. If delivery was expected before completing the course, the second dose of BM could be administered $12 \mathrm{~h}$ after the initial dose $(n=17)$. Administration of an additional single dose of $12 \mathrm{mg}$ was considered if the interval between the first course and delivery exceeded 7 days.

Patient data were retrieved from electronic patient journals. Confirmed chorioamnionitis was diagnosed by amniotic fluid puncture findings or by histopathological examination of the placenta and membranes. ${ }^{18,19}$ For analyses involving chorioamnionitis, 16 infants for whom the exposure to chorioamnionitis was unclear were excluded. Of these infants, 12 were born following clinician suspicion of chorioamnionitis, but without confirmation by amniotic fluid or placental histopathological examination and 4 were born after preterm labor with or without PPROM, but lacking placental histopathological examination. RDS was recorded according to the clinician-made diagnosis (www.vtoxford.org). Three infants died, one of them during the neonatal period at 13 days of age. The clinical characteristics of the infants are shown in Table 1.

Data on oxygen demand were retrieved from the electronic patient information system (Centricity Critical Care Clinisoft, GE Healthcare Europe, Helsinki, Finland). The mean oxygen supplementation for the first $72 \mathrm{~h}$ postnatally was calculated as a proxy for the severity of acute respiratory illness.

GC concentration analysis

At delivery, umbilical cord blood was collected in sterile tubes containing sodium citrate or EDTA. The plasma was separated at 4 ${ }^{\circ} \mathrm{C}$ and stored at $-80^{\circ} \mathrm{C}$. We measured cortisol and $\mathrm{BM}$ concentrations by liquid chromatography-tandem mass spectrometry (LC-MS/MS). Before analysis, $40 \mu \mathrm{L}$ of $0.25 \mu \mathrm{M}$ deuterated $\mathrm{BM}$ and deuterated cortisol as internal standards (D3-cortisol, Cambridge Isotope Laboratories, Andover, MA, USA; D5-BM, Medical Isotopes Inc., Pelham, NH, USA) in 50\% (vol/vol) methanol was added to $50 \mu \mathrm{L}$ of plasma before extraction with $3 \mathrm{~mL}$ of dichlormethane. After mixing for $3 \mathrm{~min}$, the organic phase was evaporated to dryness under nitrogen. The residue was dissolved in $0.5 \mathrm{~mL}$ of $40 \%$ methanol. Calibrators containing $1-500 \mathrm{nmol} / \mathrm{L}$ of BM (Riedel-de Haën, Buchs, Switzerland) and cortisol (Sigma, St. Louis, Mo., USA) were prepared in $40 \%$ methanol. Twenty microliters of sample extracts and calibrators were analyzed on a LC-MS/MS system equipped with an API 4000 triple quadrupole mass spectrometer (AB Sciex, Concord, ON, Canada). Peripherals included an Agilent series 1200 HPLC system with a binary pump. Separation was performed on a SunFire C18 column $(3.5 \mu \mathrm{m}, 2.1 \times$ $50 \mathrm{~mm}^{2}$; Waters, Milford, MA, USA). The mobile phase was a linear gradient consisting of methanol and water, at a flow rate of 300 $\mu \mathrm{L} / \mathrm{min}$. The gradient was $0 \mathrm{~min}, 40 \%$ methanol; $2 \mathrm{~min}, 100 \%$ methanol; 2-4 $\mathrm{min}, 100 \%$ methanol; and $4.5-10 \mathrm{~min}, 40 \%$ methanol. The column was directly connected to the electrospray ionization probe. Cortisol and BM were detected in the negative 
mode with the following transitions: $\mathrm{m} / \mathrm{z}$ 391.5-361.5 (BM), $\mathrm{m} / \mathrm{z}$ 396.5-364.5 (IS-BM), $\mathrm{m} / \mathrm{z}$ 361.2-331.2 (cortisol), and $\mathrm{m} / \mathrm{z}$ 364.2-334.1 (IS-cortisol). Data were acquired and processed with the Analyst Software (Ver. 1.4; AB Sciex). The mass calibration and resolution adjustments (at 0.7 atomic mass units at full width and half height) on both the resolving quadrupoles were optimized using a polypropylene glycol solution with an infusion pump. The limit of detection (S/N 3) for BM and cortisol was 0.05 and 0.03 $\mathrm{nmol} / \mathrm{L}$, respectively. We calculated the total GC concentration as the sum of cortisol equivalents $(\mathrm{ng} / \mathrm{mL})$ of $B M$ and cortisol (equivalence ratio $33.3: 1)^{20}$ with $1 \mathrm{nmol} / \mathrm{L}$ of cortisol corresponding to $0.362 \mathrm{ng} / \mathrm{mL}$ and $1 \mathrm{nmol} / \mathrm{L} B M$ to $0.393 \mathrm{ng} / \mathrm{mL}$.

Quantitation of gene expression

We obtained nasal epithelial cell samples via gentle scraping of the infants' nostrils $<2 \mathrm{~h}$ (46 [20-100] $\mathrm{min})$ and at 1 day (24.8 [19.6$33.4] \mathrm{h}$ ) postnatally. Preparation and quantitation of the RNA and reverse transcription-polymerase chain reactions of $\alpha-, \beta-$, and $\gamma \mathrm{ENaC}$, a1- and $\beta 1 \mathrm{Na}, \mathrm{K}-\mathrm{ATP}$ ase, and SGK1 were performed as before. ${ }^{21,22}$ In brief, we dispersed the cell samples in a lysis buffer (RLT, RNEasy, Qiagen, Valencia, CA) containing $10 \mu \mathrm{L} \beta$ mercaptoethanol per $10 \mathrm{~mL}$ of buffer and, after initial freezing at $-20^{\circ} \mathrm{C}$, stored them at $-80^{\circ} \mathrm{C}$. Purification of total RNA was performed with the RNEasy Kit (Qiagen, Valencia, CA), and quantitation and purity of RNA were assessed with a NanoDrop spectrophotometer (Thermo Fisher Scientific, Wilmington, DE). We used the TATAA GrandScript RT Reaction Mix 5× (TATAA Biocenter, Gothenburg, Sweden) for the RT reactions and TaqMan Universal PCR Master Mix (Applied Biosystems/Thermo Fisher Scientific, Foster City, CA) for the subsequent PCR of the complementary DNA. Predeveloped TaqMan assays were used for $\alpha^{-}, \beta$-, and үENaC, a1 Na,K-ATPase, and SGK1 (Applied Biosystems/Thermo Fisher Scientific) quantitative real-time PCR (ABI Prism 7900 Sequence Detection System, Applied Biosystems/Thermo Fisher Scientific). The $\beta 1 \mathrm{Na}, \mathrm{K}-\mathrm{ATP}$ ase and the epithelial cell marker cytokeratin 18 (CK18) used for normalization of the data were designed with the Primer Blast and Beacon designer. ${ }^{22}$ On each PCR plate, an internal calibrator was included and relative amounts of the messenger RNAs (mRNAs) were calculated according to the $\Delta \Delta \mathrm{Ct}$ algorithm.

Statistical analysis

Between-group comparisons were performed with Student's $t$ test or Mann-Whitney $U$ test. Wilcoxon's signed-rank test was conducted for comparison of repeated measurements.
Associations between the categorical variables and the groups were assessed with Pearson's $X^{2}$ or Fisher's exact test. Correlations were assessed with Spearman's rank-order correlation. For correlations between mean oxygen supplementation and GC concentrations, a subgroup analysis restricted to infants with at least $24 \mathrm{~h}$ of BM exposure was performed based on the expected lag in BM effects. ${ }^{8}$

Multiple linear regression and logarithmic regression analyses were performed to assess associations between study parameters, with log transformation as appropriate. However, for the expression data the fitted regression models violated the model assumptions due to non-normal and/or heteroscedastic residuals.

Data are presented as median (range), unless indicated otherwise. A two-sided $p$ value $<0.05$ was considered statistically significant. Statistical analyses were performed with SPSS version 25.0 (IBM SPSS Statistics, IBM Corporation, Armonk, NY) and R version 3.6.1.

\section{RESULTS}

GCs in umbilical cord blood

Sufficient amounts of cord blood for GC analyses were available in 55 infants. All mothers with GC concentration results received at least one single dose of $12 \mathrm{mg} \mathrm{BM}$, but none more than four doses (Table 2). The timing and concentrations of BM are reported in Table 2 and Supplementary Table S1. The GC data included three outliers with $\mathrm{BM}$ concentrations $\geq 20 \mathrm{ng} / \mathrm{mL}$. These outliers were removed from statistical analyses.

In cord blood, the BM and total GC concentrations correlated with the length of the time interval between the first $(r=-0.371$, $p=0.007, n=52$ and $r=-0.305, p=0.028, n=52)$ and last $(r=$ $-0.939, p<0.001, n=52$ and $r=-0.820, p<0.001, n=52$ ) dose of $\mathrm{BM}$ and birth. The correlation between BM concentrations and time since the last dose in infants delivered within 7 days of the last dose is shown in Fig. 1. The cortisol concentration correlated with the timing of the last BM dose $(r=0.433, p=0.001, n=55)$. An inverse correlation existed between the concentrations of cortisol and BM ( $r=-0.385, p=0.005, n=52)$.

In infants of mothers with chorioamnionitis, cortisol concentrations were higher than in infants of mothers without chorioamnionitis (6.7 [1.8-32.9] vs. $3.4[0.6-20.3] \mathrm{ng} / \mathrm{mL}, p=0.008, n=14$ and $n=29)$. No difference in BM concentrations (1.3 (0.06-14.5) vs. $1.2(0.05-11.6) \mathrm{ng} / \mathrm{mL}, p=0.57)$ or timing of its last dose $(42.9$ [3.7-642.0] vs. 67.8 [7.3-362.0] $\mathrm{h}, p=0.59)$ existed. In a regression analysis, only the presence of chorioamnionitis $(\beta \quad 0.65,95 \%$

Table 2. Administration of maternal antenatal betamethasone and umbilical cord blood concentrations of glucocorticoids.

\begin{tabular}{|c|c|c|c|c|}
\hline & All infants $\left(n=62^{\mathrm{a}}\right)$ & $\operatorname{RDS}(n=27)$ & No $\operatorname{RDS}(n=36)$ & $P$ value (RDS vs. no RDS) \\
\hline First dose of BM ( $h$ antenatally & $\begin{array}{l}168.8(7.7-1449.0) \\
197.3(7.7-1449.0)^{b}\end{array}$ & $\begin{array}{l}172.8(7.7-920.3) \\
209.3(7.7-920.3)^{b}\end{array}$ & $\begin{array}{l}124.3(17.9-1449.0) \\
185.3(17.9-1449.0)^{b}\end{array}$ & $\begin{array}{l}0.94 \\
0.83\end{array}$ \\
\hline Last dose of BM (h antenatally) & $\begin{array}{l}68.1(2.3-719.0) \\
67.8(2.3-642.0)^{b}\end{array}$ & $\begin{array}{l}74.6(2.3-719.0) \\
102.2(7.25-456.0)^{b}\end{array}$ & $\begin{array}{l}38.5(3.7-642.0) \\
42.9(3.7-642.0)^{b}\end{array}$ & $\begin{array}{l}0.20 \\
0.10\end{array}$ \\
\hline Cord blood cortisol (ng/mL) & $\begin{array}{l}4.7(0.6-32.9) \\
n=55\end{array}$ & $\begin{array}{l}4.3(1.1-24.6) \\
n=23\end{array}$ & $\begin{array}{l}4.9(0.6-121.6) \\
n=32\end{array}$ & 0.84 \\
\hline $\begin{array}{l}\text { Total GC concentration }(\mathrm{ng} / \mathrm{mL} \text { cortisol } \\
\text { equivalents) }{ }^{\mathrm{c}}\end{array}$ & $\begin{array}{l}40.4(4.6-487.0) \\
n=52\end{array}$ & $\begin{array}{l}19.9(4.6-368.9) \\
n=21\end{array}$ & $\begin{array}{l}55.3(6.4-487.0) \\
n=31\end{array}$ & 0.002 \\
\hline \multicolumn{5}{|c|}{$\begin{array}{l}B M \text { betamethasone, } G C \text { glucocorticoid, } R D S \text { respiratory distress syndrome. } \\
\text { Data presented as median (range), unless otherwise indicated. } \\
\text { aTwo infants whose mothers received dexamethasone excluded. } \\
\text { bIndividuals with available BM concentration only ( } n=52) \text {, three outliers excluded. } \\
\text { 'Three BM outliers excluded. }\end{array}$} \\
\hline
\end{tabular}




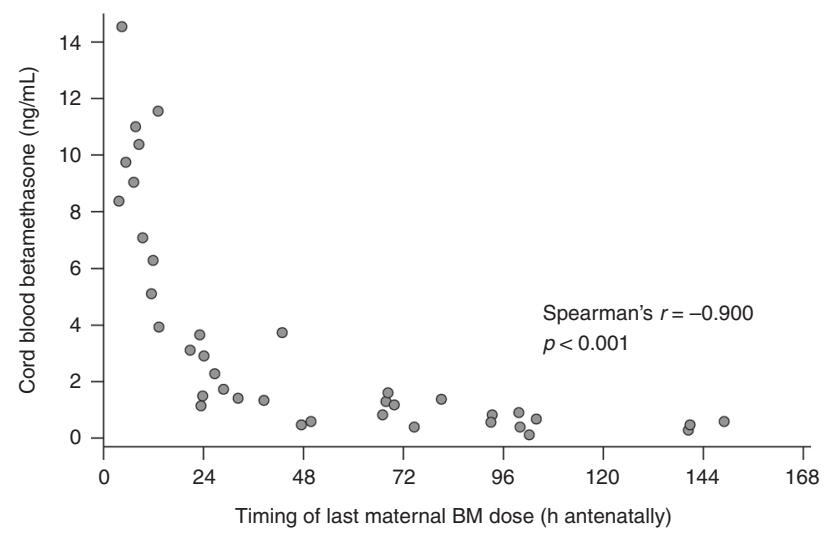

Fig. 1 Umbilical cord blood betamethasone concentrations. Correlation of umbilical cord blood betamethasone concentrations with time from admininstration of the last dose in infants exposed to the last dose of betamethasone $0-7$ days before delivery $(n=38)$.

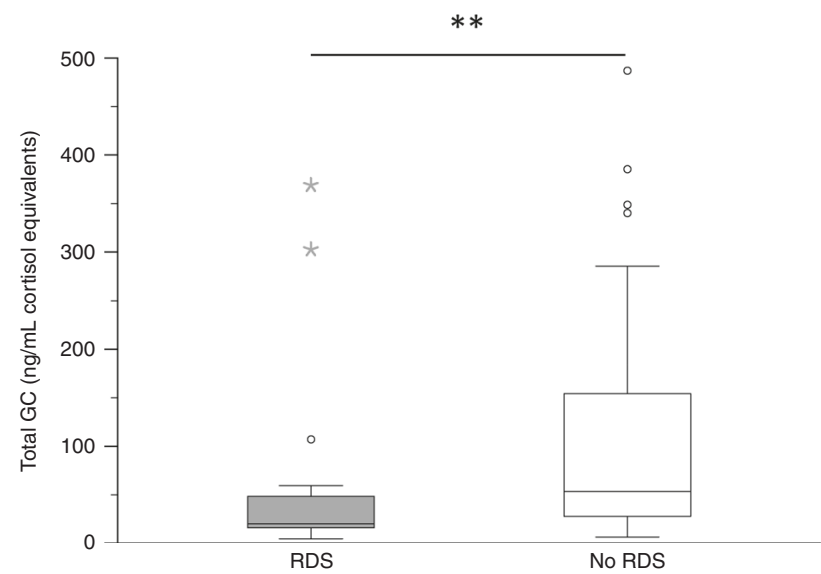

Fig. 2 Total glucocorticoid concentrations and RDS. Umbilical cord blood total glucocorticoid concentrations as cortisol equivalents in infants with $(n=21)$ and without RDS $(n=31)$. RDS respiratory distress syndrome, GC glucocorticoid. ${ }^{* *} p<0.01$. Mann-Whitney $U$ test.

confidence interval $(\mathrm{Cl}): 0.11-1.19, p=0.021)$, but not the $\mathrm{BM}$ concentration or the timing of the last dose, associated with the logarithm of the cortisol concentration.

GCs and respiratory morbidity

In infants with RDS, the cord blood concentrations of $\mathrm{BM}$ ( $p=$ $0.015)$ and total GC $(p=0.002)$, but not of cortisol $(p=0.84)$, were lower than in infants without RDS (Table 2 and Fig. 2). The timing of BM did not differ between infants with and without RDS $(p \geq$ 0.10 ) (Table 2). In a regression model, both the logarithm of the BM concentration (odds ratio (OR) $0.33,95 \% \mathrm{Cl}: 0.14-0.65, p=$ 0.004 ) and the timing of the last dose (OR $0.99,95 \% \mathrm{Cl} 0.98-1.00$, $p=0.028$ ) lowered the odds for RDS. No statistically significant difference in GA existed between infants with and without RDS $(p=0.07)$ (Table 1).

Mean $\mathrm{O}_{2}$ supplementation from 0 to $72 \mathrm{~h}$ postnatally correlated negatively with GA $(r=-0.267, p=0.033, n=64)$, while between 0 and $24 \mathrm{~h}$ the correlation was not statistically significant $(p=0.052)$. In all infants, mean $\mathrm{O}_{2}$ supplementation did not correlate with timing of BM or concentrations of GCs (all $p>0.09)$. In contrast, in infants where the first or repeat dose of BM was administered $24 \mathrm{~h}$ or more before delivery $(n=50)$, mean oxygen supplementation $0-24$ and $0-72 \mathrm{~h}$ postnatally correlated negatively with the BM $(r=-0.368, p=0.015, n=43$
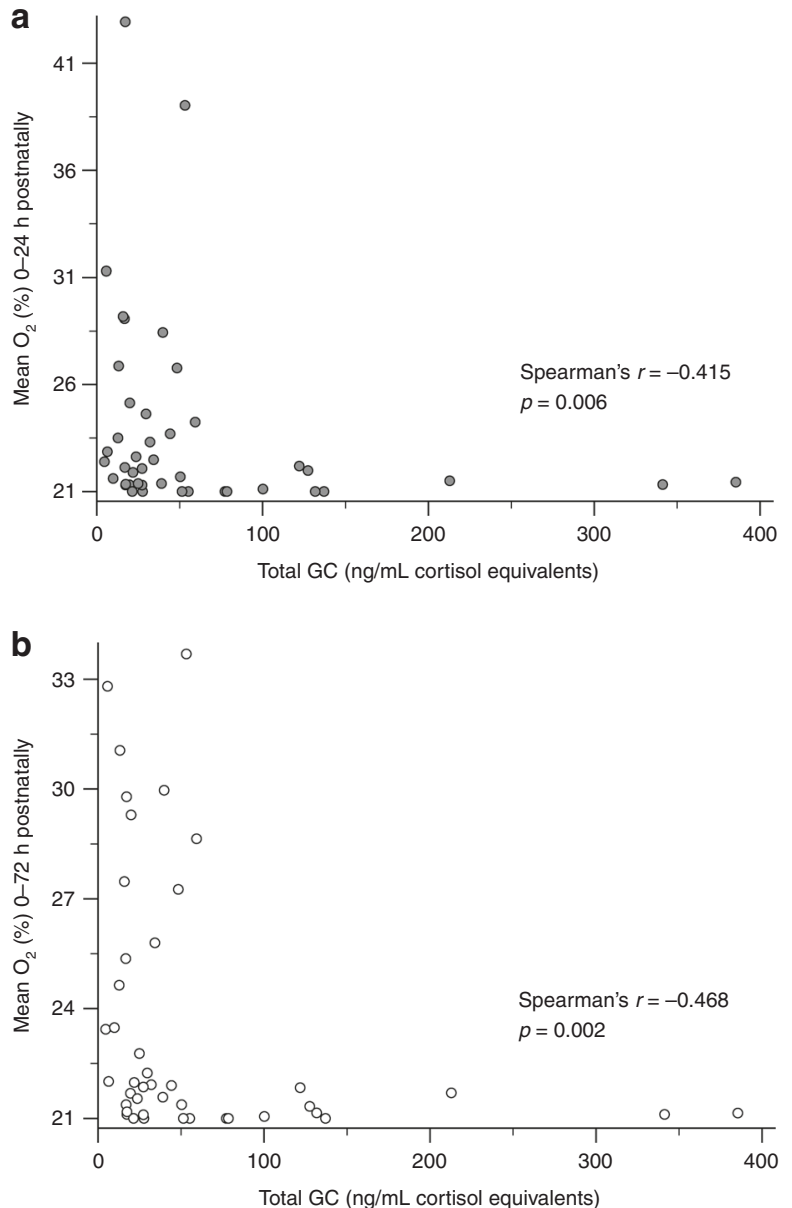

Fig. 3 Mean oxygen supplementation and total GC concentrations. Correlation of mean oxygen supplementation $\mathbf{a} 0-24 \mathrm{~h}$ and $\mathbf{b}$ 0-72 $\mathrm{h}$ postnatally with cord blood total glucocorticoid concentrations when the first or repeat dose of betamethasone was administered at least $24 \mathrm{~h}$ antenatally $(n=43)$.

and $r=-0.429, p=0.004, n=43)$ and total GC concentrations (Fig. 3). In infants exposed to chorioamnionitis $(n=14)$, the mean $\mathrm{O}_{2}$ supplementation $0-24$ and $0-72 \mathrm{~h}$ postnatally was lower than in infants not exposed $(n=34)(21.4$ [21.0-35.8] vs. $24.0[21.0-39.0] \%, p=0.036$ and $21.1[21.0-28.5]$ and 25.0 $[21.0-37.1] \%, p=0.004)$.

GCs and gene expression of sodium transport mediators

The expression of aENaC $(r=0.407, p=0.048, n=24)$, a1 Na, KATPase $(r=0.497, p=0.011, n=25)$, and $\beta 1 \mathrm{Na}, \mathrm{K}-\mathrm{ATPase}(r=$ $0.486, p=0.014, n=25)$ at $<2 \mathrm{~h}$ postnatally correlated with cord $\mathrm{BM}$ and total GC concentrations (Fig. 4). At $<2 \mathrm{~h}$ postnatally, no significant correlations between aENaC $(r=-0.349, p=0.07, n=$ $28)$, a1Na,K-ATPase $(r=-0.315, p=0.09, n=30)$, or $\beta 1 \mathrm{Na}, \mathrm{K}-$ ATPase $(r=-0.337, p=0.07, n=30)$ mRNA amounts and the time from last BM existed.

Mediators of sodium transport and respiratory morbidity

The expression of $\mathrm{a} 1-$ and $\beta 1 \mathrm{Na}, \mathrm{K}-\mathrm{ATP}$ ase at $<2 \mathrm{~h}$ was lower in infants with RDS than in those without $(p=0.013$ and 0.030$)$ (Fig. 5). No other differences in expression of ENaC, Na,K-ATPase, or SGK1 existed (all $p>0.21$ ).

No correlations existed between $\alpha-, \beta-$, or $\gamma \mathrm{ENaC}, \alpha 1-$, or $\beta 1 \mathrm{Na}, \mathrm{K}-$ ATPase, or SGK1 mRNA at $<2 \mathrm{~h}$ or at 1 day and mean oxygen demand during the first 72 postnatal hours (all $p>0.06$ ). 


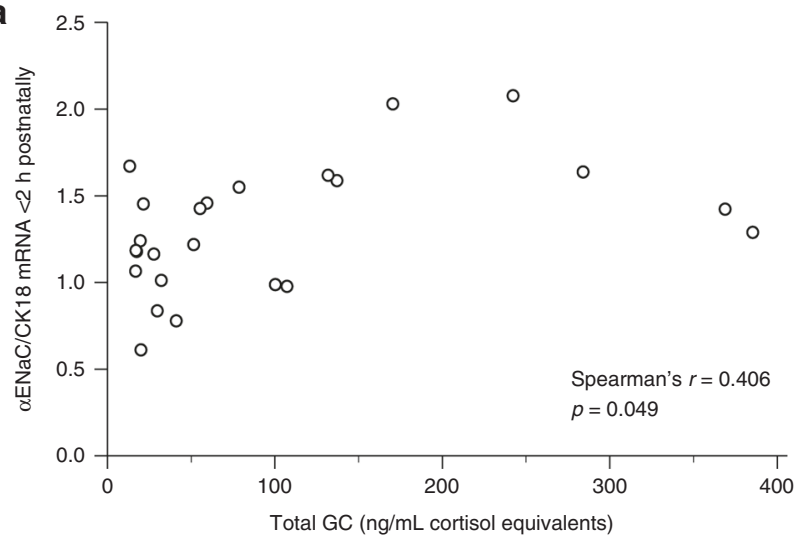

b
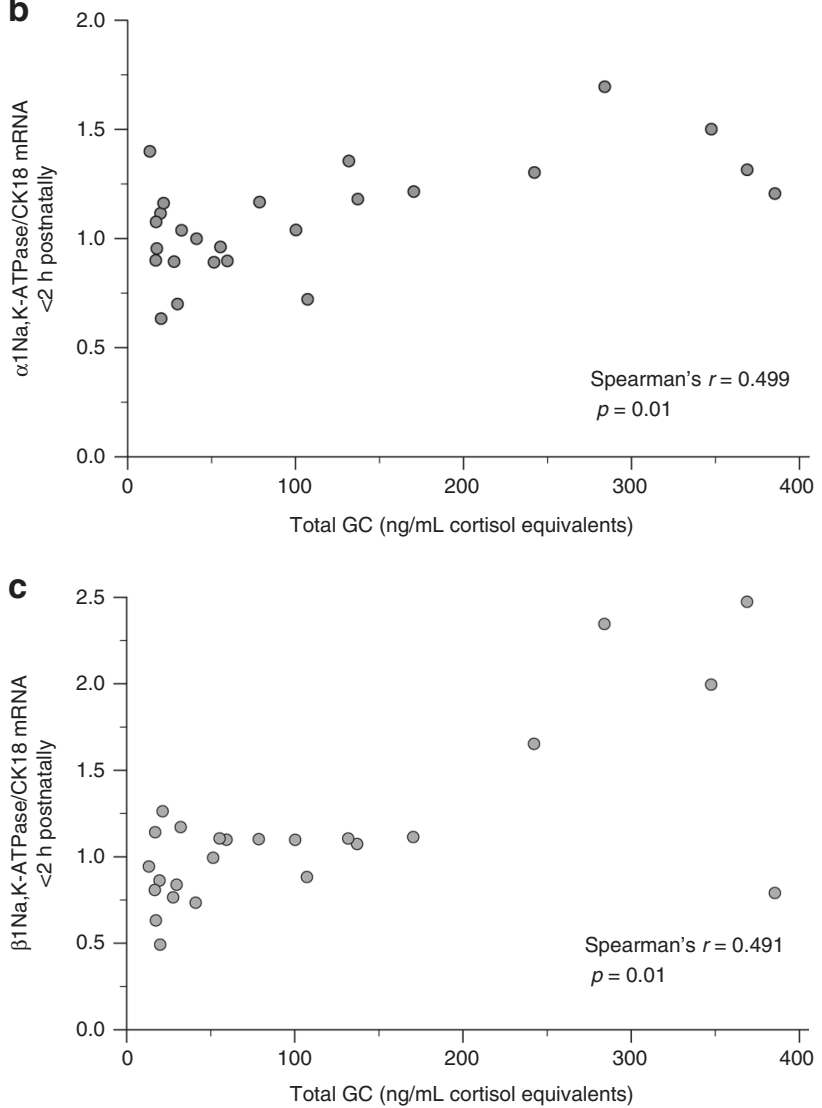

Fig. 4 Sodium transporter gene expression and total GC concentrations. Correlations of a $\alpha \mathrm{ENaC}(n=24), \mathbf{b} \alpha 1-$, and c $\beta 1 \mathrm{Na}, \mathrm{K}-\mathrm{ATPase}(n=25)<2 \mathrm{~h}$ postnatally with total glucocorticoid concentrations. GC glucocorticoid.

In infants exposed to chorioamnionitis, the expression of SGK1 at $<2 \mathrm{~h}$ was higher than in those not exposed (1.6 [0.7-3.5] vs. 0.7 [0.3-2.1] SGK1/CK18 mRNA, $p=0.003, n=9$, and $n=16)$.

Mediators of sodium transport and GA

At $<2 \mathrm{~h}$ postnatally, the expression of $\mathrm{a}-$ and $\beta \mathrm{ENaC}$, and $\mathrm{a} 1 \mathrm{Na}, \mathrm{K}-$ ATPase correlated positively with GA $(r=0.377, p=0.040, n=30$; $r=0.516, p=0.002, n=32$; and $r=0.354, p=0.047, n=32$ ). At 1 day postnatally, $\beta 1 \mathrm{Na}, \mathrm{K}-\mathrm{ATP}$ ase expression correlated with GA $(r=0.381, p=0.045, n=28)$, while at $<2 \mathrm{~h}$ the correlation did not reach statistical significance (Spearman's $r=0.335, p=0.061, n=$ 32). No correlation between $y \mathrm{ENaC}$ or SGK1 expression and GA existed $(p>0.2)$. In addition, $\beta$ - and $\gamma \mathrm{ENaC}$, and $\alpha 1-$ and $\beta 1 \mathrm{Na}, \mathrm{K}$ -

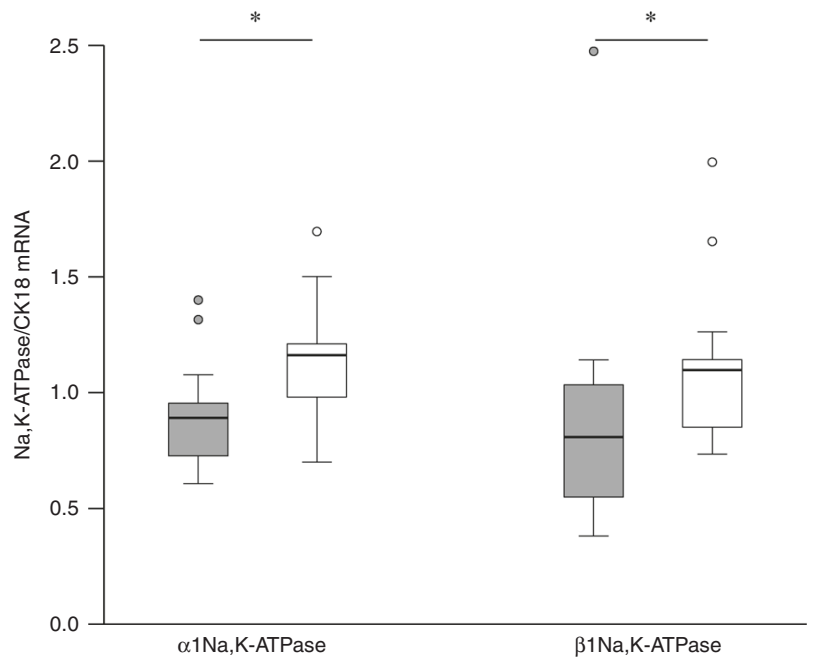

Fig. 5 RDS and sodium transporter gene expression. Expression of $\alpha 1-$ and $\beta 1 \mathrm{Na}, \mathrm{K}-\mathrm{ATPase}$ in airway epithelium at $<2 \mathrm{~h}$ postnatally in infants with ( $n=13$; shaded boxes) and without $(n=19$; white boxes) RDS. RDS respiratory distress syndrome. ${ }^{*} p<0.05$. Mann-Whitney $U$ test.

ATPase subunits mRNA decreased significantly between $<2 \mathrm{~h}$ and 1 day postnatally (Table 3 ).

\section{DISCUSSION}

This study used nasal airway gene expression of sodium ion transport mediators associated with lung liquid clearance as a substitute for the end-organ response to GCs. It demonstrates that the expression of subunits of $\mathrm{ENaC}$ and $\mathrm{Na}$, K-ATPase associates with GC concentrations in newborn preterm infants and indicates that antenatal BM upregulates $\mathrm{aENaC}$ and $\mathrm{Na}, \mathrm{K}-\mathrm{ATPase}$ subunits in the airway and respiratory epithelium. Furthermore, the expression of $\mathrm{Na}, \mathrm{K}-\mathrm{ATP}$ ase subunits as well as the BM and total GC concentrations in umbilical cord blood were lower in infants with RDS. We suggest that induction of airway and lung epithelial sodium transporters may be a mechanism contributing to the beneficial effects of antenatal GCs on respiratory morbidity in the preterm newborn infant.

Animal data show that antenatal GCs, in addition to enhancing the synthesis of surfactant, also reduce lung liquid content during the first postnatal hours. ${ }^{7}$ Substantial in vitro and animal data exist on induction of sodium transporters $\mathrm{ENaC}$ and $\mathrm{Na}$, K-ATPase by GCs in the respiratory epithelium. ${ }^{16,23-25}$ In human late preterm and term infants, expression of subunits of $\mathrm{ENaC}$ in the airway epithelium associates with the concentrations of cortisol in cord blood and saliva. ${ }^{26,27}$ In ventilator-dependent preterm infants, $\mathrm{ENaC}$ expression is increased by dexamethasone. ${ }^{21}$ In this study, we show that the airway epithelial gene expression of aENaC, a1-, and $\beta 1 \mathrm{Na}, \mathrm{K}-\mathrm{ATPa} e$ during the immediate postnatal period correlates with cord blood BM and total GC concentrations in preterm infants $<32$ weeks of gestation. In addition, as the expression of $\mathrm{Na}$, K-ATPase subunits was lower in infants with RDS, we speculate that induction of sodium ion transporters by antenatal BM could be related to more efficient lung liquid clearance and could thus contribute to improved pulmonary adaptation.

In humans, the optimal interval between the first dose of antenatal GC treatment and birth is $1-7$ days. ${ }^{2,28}$ However, little human data on the optimal concentration of GCs exist. ${ }^{28}$ In our study, infants with RDS had lower total GC concentrations than infants without RDS. Furthermore, in infants exposed to the first or repeat dose of BM for $>24 \mathrm{~h}$, mean oxygen supplementation during the first $72 \mathrm{~h}$ correlated negatively with GC concentrations. 
Table 3. Airway gene expression of ENaC, Na,K-ATPase, and SGK1 at $<2 \mathrm{~h}$ and at 1 day postnatally.

\begin{tabular}{|c|c|c|c|}
\hline & $<2 \mathrm{~h}$ postnatally & 1 day postnatally & $P$ value \\
\hline$\beta \mathrm{ENaC} / \mathrm{CK} 18$ mRNA $(n=20)$ & $1.1(0.6-1.7)$ & $0.5(0.03-0.9)$ & $<0.001$ \\
\hline$\alpha 1 \mathrm{Na}, \mathrm{K}-\mathrm{ATPase} / \mathrm{CK} 18 \mathrm{mRNA}(n=20)$ & $1.0(0.7-1.5)$ & $0.8(0.5-1.6)$ & 0.005 \\
\hline$\beta 1 \mathrm{Na}, \mathrm{K}-\mathrm{ATPase} / \mathrm{CK} 18$ mRNA $(n=20)$ & $1.0(0.6-2.5)$ & $0.7(0.5-1.7)$ & 0.001 \\
\hline
\end{tabular}

Data are presented as median (range).

ENaC epithelial sodium channel, CK18 cytokeratin 18, SGK1 serum- and glucocorticoid-inducible kinase 1.

These findings indicate that not only the timing of antenatal GCs, but also the resulting concentrations are important for their pulmonary effects. Interestingly, the median BM concentration in infants without RDS is within the range that, in animal studies, induces a pulmonary maturational response.

In pregnant women receiving standard BM treatment, that is, two doses of $12 \mathrm{mg} \mathrm{BM}$ at a 24-h interval, due to threatening preterm labor, the distribution of the drug follows a twocompartment model $^{29}$ with first-order elimination kinetics. ${ }^{30}$ In maternal blood the $\mathrm{GC}$ bioactivity due to BM peaks within $1 \mathrm{~h}$ post administration, when it can also be detected in cord blood. ${ }^{28,30}$ The mean gradient of BM in maternal and cord blood is $3: 1 .^{28}$ The mean elimination half-life of BM in the maternal circulation is 6-8 $\mathrm{h},{ }^{28-30}$ but in the fetus about twice as long. ${ }^{28}$ Our data confirm the existence of a strong correlation between the time since the last dose of BM and umbilical cord blood BM concentrations. ${ }^{30}$ However, the range of GC concentrations for an optimal molecular and functional pulmonary response may be narrow. The GC doses used with antenatal treatment are likely to exceed the dose required for maximal stimulation of sodium ion transporter gene expression. ${ }^{23,31}$ Indeed, animal experiments show that in fetal lung one-quarter of the clinically used antenatal GC dose induces, in addition to gene expression of surfactant proteins, gene expression of ENaC subunits. ${ }^{32}$ Furthermore, animal data indicate that a fetal plasma BM concentration $\sim 1-4 \mathrm{ng} / \mathrm{mL}$ is sufficient for molecular and functional lung maturation, provided sufficient duration of the exposure. ${ }^{8}$ In our study, if the time from GC administration was $<24 \mathrm{~h}$, the median concentration of BM in cord blood was clearly higher (Fig. 1 and Supplementary Table S1). In contrast, already $48 \mathrm{~h}$ after the last BM dose, the BM concentrations in most infants had fallen below the lower concentration limit for a molecular and functional pulmonary maturational response (Fig. 1). ${ }^{8}$ Considering that the phosphate form of BM results in higher peak concentrations, while the acetate form has a slow-release profile with a longer half-life, our data underline the need for optimization not only of BM doses but possibly also of its formulation. ${ }^{8}$

In addition to the concentrations of antenatal GCs, the time of exposure is relevant to the transcriptional response and functional effects. $^{8,32}$ Our finding that aENaC, a1-, and $\beta 1 \mathrm{Na}, \mathrm{K}$-ATPase mRNA $<2 \mathrm{~h}$ postnatally correlates with $\mathrm{GC}$ is in line with their transcriptional response to GCs occurring within hours. ${ }^{16,23-25,33}$ The lack of correlations between $\beta$ - and $\gamma \mathrm{ENaC}$, and SGK1 expression and $\mathrm{BM}$ or total GC concentrations may be related to the differing timing of their transcriptional response: augmentation of $\beta$ - and $\gamma \mathrm{ENaC}$ gene expression may require even $48 \mathrm{~h}$ of GC exposure, ${ }^{25}$ while induction of SGK1 expression by GCs reaches its maximum in $1 \mathrm{~h} .{ }^{24}$ Furthermore, SGK1 is induced by various other stimuli including inflammatory cytokines. ${ }^{34}$ Interestingly, the expression of SGK1 was higher in infants to mothers with chorioamnionitis. Chorioamnionitis is associated with an increase in inflammatory cytokines ${ }^{35}$ that can upregulate the gene expression of SGK1. ${ }^{34}$ Induction of SGK1 could, in turn, be related to augmentation of $\mathrm{ENaC}$ and $\mathrm{Na}, \mathrm{K}-\mathrm{ATP}$ ase and thus enhanced lung liquid clearance. ${ }^{10}$ Indeed, in our study a greater proportion of infants without RDS had been exposed to chorioamnionitis. This is in agreement with an earlier study in very low birthweight infants, where chorioamnionitis was associated with less respiratory distress. ${ }^{36}$ Additionally, both the present and the previous study $^{36}$ show higher levels of cord blood cortisol in infants exposed to chorioamnionitis. These higher concentrations of cord blood cortisol in infants exposed to confirmed chorioamnionitis are likely to represent the physiologic response to inflammation. ${ }^{36}$ An increase in cortisol was proposed to induce a pulmonary maturational response. ${ }^{36}$ In contrast, later animal studies have suggested that the increase in cortisol induced by an inflammatory stimulus is insufficient to result in improved lung function. ${ }^{37}$ However, there are additive lung maturational effects of chorioamnionitis and antenatal GCs. ${ }^{37}$ Interestingly, in our study the infants with RDS had both lower cord blood BM concentrations and were less often exposed to chorioamnionitis. These infants thus seem to be deficient in two important stimuli for lung maturation in preterm infants.

In a previous population of preterm and term infants, we showed that the expression of subunits of $\mathrm{ENaC}$ in the nasal airway epithelium correlates with $\mathrm{GA} .{ }^{38}$ Here, we demonstrate that even before 32 weeks $G A$, in addition to $\alpha$ - and $\beta E N a C$, the gene expression of a1Na,K-ATPase in human newborn infants increases with advancing GA. A peak in the expression may occur around birth, since during the first postnatal day both $\beta$ - and $\gamma E N a C$ and a1- and $\beta 1 \mathrm{Na}, \mathrm{K}-\mathrm{ATPase}$ mRNA amounts fall significantly. This pattern of expression is in line with the importance of these ion transporter subunits during the pronounced requirement for lung liquid clearance during pulmonary adaptation.

We acknowledge some limitations to our study. Maternal factors, such as lean body weight, may affect maternal and thus fetal BM concentrations. ${ }^{29}$ We did not adjust for maternal weight in analysis since our key results are based on actual GC concentrations rendering maternal factors less important. However, in optimization of antenatal GC treatment, for example, by targeting lower BM concentrations, maternal lean body weight may become significant since the reported lack of differences in neonatal outcomes depending on maternal body size may be related to higher, supratherapeutic dosing. ${ }^{29}$

Exploring a potential effect of different dosing schedules on the resulting $\mathrm{BM}$ concentrations in relation to treatment timing would have been of interest. However, our study population included infants exposed to differing dosing schedules: in addition to the standard treatment course of two doses of $12 \mathrm{mg} \mathrm{BM}$ at a 24-h interval, in some infants their mothers had received the doses with a shorter 12-h interval. Furthermore, part of the infants was exposed only to a single dose of BM or to a repeat dose following an earlier complete course. Due to this lack of uniformity in dosing schedules, we did not include them in our analysis. 
The transcutaneous oxygen target range differed between infants delivered in 2007/2008 and 2011 to 2013. In the earlier time period, the target range was $88-94 \%$. Due to the BOOST IItrial, $^{39}$ in 2011 the saturation target range was changed to $90-95 \%$. However, since the difference in targeted range is small, we consider any significant effect on mean oxygen supplementation results unlikely.

We did not study the effects of BM on surfactant. However, this has been extensively explored previously, and here we focused on a possible additional contributing mechanism to the beneficial pulmonary effects of antenatal GCs.

Although our gene expression data originate from the nasal epithelium, an association between nasal epithelial ion transport and both lung function and morbidity exists. ${ }^{15,40,41}$ Importantly, in the clinical setting more invasive sampling comes with ethical considerations. Furthermore, the expression data are limited to the gene transcription level. It is evident that regulation of ion transport also occurs at the post-transcriptional and posttranslational level. However, increases in ion transporter activity have been shown to occur in parallel with the increase of their gene expression. ${ }^{33}$

\section{CONCLUSION}

This study indicates that antenatal BM upregulates ion transporters in the airway epithelium of preterm infants. Considering the upper airway as reflective of distal airway epithelium, this could constitute a mechanism through which antenatal BM promotes lung liquid clearance and pulmonary adaptation. Thus, the association of an improved respiratory outcome after preterm delivery with higher cord blood GC concentrations may, in part, be mediated via upregulation of airway and respiratory epithelial sodium transporters.

\section{ACKNOWLEDGEMENTS}

We thank the personnel at the maternal and delivery wards of the Women's Hospital and the NICU nurses at the Children's Hospital, Helsinki University Hospital for thei kind assistance during recruitment and sample collection. Ms. Marita Suni and Ms. Sari Lindén are thanked for help with data acquisition and laboratory analysis. We also are grateful for the contributions of Associate Professor Petteri Hovi and statistician Mitja Lääperi for statistical analyses. This work was funded by Finska Läkaresällskapet, Foundation for Pediatric Research in Finland, the Finnish Special Governmental Subsidy for Health Sciences.

\section{AUTHOR CONTRIBUTIONS}

L.S. and A.C.J. conceptualized and designed the study, collected data, carried out the initial analyses, drafted the initial manuscript, and completed its final submitted version. P.A.P. and S.A. conceptualized and designed the study, collected data, interpreted data, and critically revised the manuscript. O.M.H. and M.A.K. conceptualized and designed the study, interpreted data, and critically revised the manuscript. M.J.L. managed data collection instruments, collected data, and critically revised the manuscript. L.U.T. designed instruments for data analyses, carried out data analyses, drafted part of the initial manuscript and critically revised the manuscript. All authors approved the final manuscript as submitted.

\section{ADDITIONAL INFORMATION}

The online version of this article (https://doi.org/10.1038/s41390-020-1061-9) contains supplementary material, which is available to authorized users.

Competing interests: The authors declare no competing interests.

Informed consent: Informed written consent to include the preterm infants in the study was obtained from the parents.

Publisher's note Springer Nature remains neutral with regard to jurisdictional claims in published maps and institutional affiliations.

\section{REFERENCES}

1. Roberts, D., Brown, J., Medley, N. \& Dalziel, S. R. Antenatal corticosteroids for accelerating fetal lung maturation for women at risk of preterm birth. Cochrane Database Syst. Rev. 3, CD004454 (2017).

2. Sweet, D. G. et al. European Consensus Guidelines on the management of respiratory distress syndrome-2019 update. Neonatology 115, 432-450 (2019).

3. Committee on Obstetric Practice. Committee Opinion No. 713: antenatal corticosteroid therapy for fetal maturation. Obstet. Gynecol. 130, e102-e109 (2017).

4. Crowther, C. A. et al. Effects of repeat prenatal corticosteroids given to women at risk of preterm birth: an individual participant data meta-analysis. PLoS Med. 16, e1002771 (2019).

5. O'Brodovich, H. M. Immature epithelial $\mathrm{Na}^{+}$channel expression is one of the pathogenetic mechanisms leading to human neonatal respiratory distress syndrome. Proc. Assoc. Am. Physicians 108, 345-355 (1996).

6. Adams, E. W. et al. Magnetic resonance imaging of lung water content and distribution in term and preterm infants. Am. J. Resp. Crit. Care Med. 166, 397-402 (2002).

7. Houeijeh, A. et al. Lung liquid clearance in preterm lambs assessed by magnetic resonance imaging. Pediatr. Res. 82, 114-121 (2017).

8. Kemp, M. W. et al. The efficacy of antenatal steroid therapy is dependent on the duration of low-concentration fetal exposure: evidence from a sheep model of pregnancy. Am. J. Obstet. Gynecol. 219, 301.e1-10 (2018).

9. McEvoy, C., Bowling, S., Williamson, K., Stewart, M. \& Durand, M. Functional residual capacity and passive compliance measurements after antenatal steroid therapy in preterm infants. Pediatr. Pulmonol. 31, 425-430 (2001).

10. Li, T., Koshy, S. \& Folkesson, H. G. IL-1beta-induced cortisol stimulates lung fluid absorption in fetal guinea pigs via SGK-mediated Nedd4-2 inhibition. Am. J. Physiol. Lung. Cell. Mol. Physiol. 296, L527-L533 (2009).

11. Siew, M. L. et al. Inspiration regulates the rate and temporal pattern of lung liquid clearance and lung aeration at birth. J. Appl. Physiol. 106, 1888-1895 (2009).

12. Blank, D. A. et al. Lung ultrasound during the initiation of breathing in healthy term and late preterm infants immediately after birth, a prospective, observational study. Resuscitation 114, 59-65 (2017).

13. O'Brodovich, H., Hannam, V., Seear, M. \& Mullen, J. B. Amiloride impairs lung water clearance in newborn guinea pigs. J. Appl. Physiol. 68, 1758-1762 (1990).

14. Hummler, E. et al. Early death due to defective neonatal lung liquid clearance in alpha-ENaC-deficient mice. Nat. Genet. 12, 325-328 (1996).

15. Barker, P. M., Gowen, C. W., Lawson, E. E. \& Knowles, M. R. Decreased sodium ion absorption across nasal epithelium of very premature infants with respiratory distress syndrome. J. Pediatr. 130, 373-377 (1997).

16. Chalaka, S., Ingbar, D. H., Sharma, R., Zhau, Z. \& Wendt, C. H. $\mathrm{Na}(+)-\mathrm{K}(+)$-ATPase gene regulation by glucocorticoids in a fetal lung epithelial cell line. Am. J. Physiol. 277, L197-L203 (1999).

17. Sakuma, T. et al. Alveolar fluid clearance in the resected human lung. Am. J. Resp. Crit. Care Med. 150, 305-310 (1994).

18. Myntti, T. et al. Amniotic fluid rapid biomarkers are associated with intra-amniotic infection in preterm pregnancies regardless of the membrane status. J. Perinatol. 36, 606-611 (2016)

19. Committee on Obstetric Practice. Committee Opinion No. 712: intrapartum management of intraamniotic infection. Obstet. Gynecol. 130, e95-e101 (2017).

20. Chrousos, G. in Basic \& Clinical Pharmacology 13th edn (eds Katzung, B. G. \& Trevor, A. J.), 680-695 (McGraw-Hill Medical, 2015).

21. Helve, O. et al. Low expression of human epithelial sodium channel in airway epithelium of preterm infants with respiratory distress. Pediatrics 113, 1267-1272 (2004).

22. Kaskinen, A. K. et al. Chronic hypoxemia in children with congenital heart defect impairs airway epithelial sodium transport. Pediatr. Crit. Care Med. 17, 45-52 (2016).

23. Venkatesh, V. C. \& Katzberg, H. D. Glucocorticoid regulation of epithelial sodium channel genes in human fetal lung. Am. J. Physiol. 273, L227-L233 (1997).

24. Itani, O. A. et al. Glucocorticoid-stimulated lung epithelial $\mathrm{Na}(+)$ transport is associated with regulated $\mathrm{ENaC}$ and sgk1 expression. Am. J. Physiol. Lung Cell. Mol. Physiol. 282, L631-L641 (2002).

25. Nakamura, K., Stokes, J. B. \& McCray, P. B. Jr. Endogenous and exogenous glucocorticoid regulation of ENaC mRNA expression in developing kidney and lung. Am. J. Physiol. Cell. Physiol. 283, C762-C772 (2002).

26. Janér, C., Pitkänen, O. M., Helve, O. \& Andersson, S. Airway expression of the epithelial sodium channel a-subunit correlates with cortisol in term newborns. Pediatrics 128, e414-e421 (2011).

27. Janér, C. et al. Duration of gestation and mode of delivery affect the genes of transepithelial sodium transport in pulmonary adaptation. Neonatology 107, 27-33 (2015)

28. Ballard, P. L., Granberg, P. \& Ballard, R. A. Glucocorticoid levels in maternal and cord serum after prenatal betamethasone therapy to prevent respiratory distress syndrome. J. Clin. Invest. 56, 1548-1554 (1975). 
Glucocorticoids, sodium transport mediators, and respiratory distress...

L Süvari et al.

1260

29. Della Torre, M., Hibbard, J. U., Jeong, H. \& Fischer, J. H. Betamethasone in pregnancy: influence of maternal body weight and multiple gestation on pharmacokinetics. Am. J. Obstet. Gynecol. 203, 254.e1-12 (2010).

30. Ballabh, P. et al. Pharmacokinetics of betamethasone in twin and singleton pregnancy. Clin. Pharmacol. Ther. 71, 39-45 (2002).

31. McTavish, N., Getty, J., Burchell, A. \& Wilson, S. M. Glucocorticoids can activate the alpha-ENaC gene promoter independently of SGK1. Biochem. J. 423, 189-197 (2009).

32. Kemp, M. W. et al. Maternofetal pharmacokinetics and fetal lung responses in chronically catheterized sheep receiving constant, low-dose infusions of betamethasone phosphate. Am. J. Obstet. Gynecol. 215, 775.e1-12 (2016).

33. Dagenais, A. et al. Modulation of alpha-ENaC and alpha1-Na+-K+-ATPase by cAMP and dexamethasone in alveolar epithelial cells. Am. J. Physiol. Lung Cell. Mol. Physiol. 281, L217-L230 (2001).

34. Lang, F., Stournaras, C., Zacharopoulou, N., Voelkl, J. \& Alesutan, I. Serum- and glucocorticoid-inducible kinase 1 and the response to cell stress. Cell Stress 3, 1-8 (2018).
35. Kunzmann, S., Speer, C. P., Jobe, A. H. \& Kramer, B. W. Antenatal inflammation induced TGF-beta1 but suppressed CTGF in preterm lungs. Am. J. Physiol. Lung Cell. Mol. Physiol. 292, L223-L231 (2007).

36. Watterberg, K. L., Scott, S. M. \& Naeye, R. L. Chorioamnionitis, cortisol, and acute lung disease in very low birth weight infants. Pediatrics 99, E6 (1997).

37. Moss, T. J. M. \& Westover, A. J. Inflammation-induced preterm lung maturation: lessons from animal experimentation. Paediatr. Respir. Rev. 23, 72-77 (2017).

38. Helve, O., Janér, C., Pitkänen, O. \& Andersson, S. Expression of the epithelial sodium channel in airway epithelium of newborn infants depends on gestational age. Pediatrics 120, 1311-1316 (2007).

39. Stenson, B. et al. Increased 36-week survival with high oxygen saturation target in extremely preterm infants. N. Engl. J. Med. 364, 1680-1682 (2011).

40. Fajac, I. et al. Relationships between nasal potential difference and respiratory function in adults with cystic fibrosis. Eur. Respir. J. 12, 1295-1300 (1998).

41. Helve, O., Pitkänen, O., Kirjavainen, T. \& Andersson, S. Sodium transport in airway epithelium correlates with lung compliance in healthy newborn infants. J. Pediatr. 146, 273-276 (2005). 